\title{
Comparative Study of the Adsorption and Desorption Behavior of Single and Multi-Ring Aromatics in Sediment Fractions
}

\author{
Chiedu N. Owabor ${ }^{1 *}$, Samuel E. Agarry², Bamidele V. Ayodele ${ }^{1}$, Ikechukwu S. Udeh', \\ Endurance Ehiosun ${ }^{1}$ \\ ${ }^{1}$ Department of Chemical Engineering, University of Benin, Benin City, Nigeria \\ ${ }^{2}$ Department of Chemical Engineering, Ladoke Akintola University, Ogbomoso, Nigeria \\ Email: "owabor4you@yahoo.com
}

Received December 4, 2012; revised January 6, 2013; accepted January 16, 2013

\begin{abstract}
The sorption behaviour of benzene, toluene, ethyl benzene, xylene and naphthalene using clay and sand sediments under ambient conditions is examined in this study. Experimental results showed that, the time taken to attain adsorption equilibrium for naphthalene, and BTEX were 28, 30, 30, 32, $28 \mathrm{hrs}$ and 20, 22, 22, 24, $22 \mathrm{hrs}$ while the desorption equilibrium time were $10,13,12,15,12 \mathrm{hrs}$ and 9,9,9,11,10 hrs in clay and sand respectively. All of the naphthalene, and BTEX were adsorbed at the different equilibrium times, using clay while the amount of naphthalene and BTEX adsorbed by sand, at different equilibrium times were 117, 121, 127, 123 and $134 \mathrm{mg}$. Following the results of the adsorption/desorption experiments, quantitative measurements showed that sand exhibited higher affinity for the solute as retained more chemicals (as high as between 58\% - 66\%) within it pores while nearly all the chemicals adsorbed by the clay were released at the attainment of equilibrium. The implication of this is that occlusion within the sand particles may likely be the resultant effect of continued sand-chemicals contact. The amount of contaminant solute adsorbed and desorbed affirmed that clay has a better capacity to retain naphthalene and BTEX than sand and this may not be unrelated to its large surface area, high porosity and higher hydraulic conductivity for the solutes arising from its good binding sites (small pore sizes) that tend to hold the adsorbates to its particles.
\end{abstract}

Keywords: Equilibrium; Kinetic Models; Pollutants; Pore Spaces; Surface Area; Permeability

\section{Introduction}

The major environmental concern in urban and industrial areas can be attributed to the increasing level of pollution particularly by substances of organic origin. Various toxic chemicals such as polycyclic aromatic hydrocarbons (PAHs): naphthalene, anthracene, benzo(a)pyrene, phenanthrene, benzene, toluene, ethyl benzene and xylene (BTEX), heavy metals and dyes are continuously discharged into the environment as industrial waste, causing water, air and soil pollutions. These chemicals due to their recalcitrant persistent nature have relatively low solubilities in water, but are highly lipophilic. The four and more condensed aromatic rings are considered to be more dangerous than the two and three rings PAHs [1-3]. The presence of these compounds which are listed as priority pollutants [4-7] in the environment is of considerable public health and ecological concern due to their toxicity to a wide range of biological systems.

*Corresponding author.
These effects apart from the degradation of the ecosystem, also results in commodity loss, loss to the communities and economic loss due to spill clean up cost.

Studies have shown that solute transport with linear equilibrium is an integral component of the degradation and/or mineralization of these toxic chemicals [8-12]. Contaminant transport is significantly viewed from two possible scenarios; fast sorption/desorption and slow sorption/desorption. Sorption tends to separate the direct contact between microorganisms and contaminants, which is necessary for biodegradation to occur. The practical effect of the adsorption and desorption rates, is that it controls the overall reaction rate of degradation process. They are one of the primary factors which affect availability, mobility and toxicity of contaminants in the soil [3-17]. They determine the measured concentration and the mechanism of distributing the contaminants into surfaces and into pores of individual soil particles [18-22] and are thus counteractive to efficient biodegradation.

Adsorption is a physical separation process in which 
certain compounds of a fluid phase are transferred to the surface of a solid adsorbent [23]. The separation is dependent on one component in a mixture being more readily adsorbed than the other components. The adsorption process takes place in three steps: macrotransport, microtransport and sorption. Macrotransport involves the movement of the organic material through the water to the liquid-solid interface by advection and diffusion. Microtransport involves the diffusion of the organic material through the macropore system of the soil particle to the adsorption sites in the micropores and submicropores of the soil particle. Adsorption results from the influence of Van der Waals forces which is essentially physical in nature. Due to the fact that the forces are not strong, the adsorption may be easily reversed. However, in some systems, additional forces bind adsorbed molecules to the solid surface. These are chemical in nature involving the exchange or sharing of electrons, or possibly molecules forming atoms or radicals. In such cases, the term chemisorption is used to describe the phenomenon [24]. This is less easily reversed than physical adsorption, and regeneration may be a problem.

The present study seeks to compare the processes of adsorption and desorption of naphthalene and BTEX in clay and sand as sediments with a view to determining the capacity and extent to which each sediment retains solutes at equilibrium as these primary processes form the basis for their availability for microbial uptake and mineralization. This is significant because in the long run results from the study will serve as a benchmark for the removal of these recalcitrant compounds which compromise the integrity of the environment. Suitable kinetic models which best describes the sorption-desorption mechanisms of the organic chemicals on the sediments will also be determined.

\section{Materials and Methods}

\subsection{Materials}

The sediments used in this study were obtained from Ikpoba River, Benin City, Edo State, Nigeria. On collection, the sediments were stored in a black polythene bag. Pretreatment of the sediments was carried out via removal of stones and other heavy particles. A $220 \mu \mathrm{m}$ mesh was used to remove the large non clay fractions from the clay and a $2.5 \mathrm{~mm}$ mesh was used to sieve the sand. Finally, they were then dried overnight at $383 \mathrm{~K}$ in a vacuum oven and stored in an air-tight container covered with a black polythene bag prior to the adsorption and desorption experiments described by [14].

The adsorbates, naphthalene, benzene, toluene, ethyl benzene and xylene were obtained from an auto-mechanic workshop at Ojota, Lagos state, Nigeria while the distilled water used for sample preparation, dilution and solution was obtained from the Department of Chemical Engineering, University of Benin, Benin City, Edo State, Nigeria.

\subsection{Methods}

\subsubsection{Adsorption-Desorption Kinetics Experiments}

The rates of adsorption by the sediments (clay and sand) were determined from the uptake levels of PAHs and BTEX from aqueous solution in batch experiments before and after contact until adsorption equilibrium was attained in the clay and sand. $100 \mathrm{~g}$ of each of the sediments (clay and sand) were mixed with $500 \mathrm{ml}$ of aqueous solution of the adsorbates at room temperature following the procedure of Owabor et al. [25]. The slurry suspensions were sampled at intervals of 2 hours and UV spectrophotometer was used for sample analysis.

\subsubsection{Adsorption Kinetics Models}

The adsorption kinetics which describes the mechanism of the adsorption process in a given system were determined in this study using pseudo-first order model as defined by Lagergren and described by Chang et al. and Sivaraj et al. [14,25], pseudo-second order model [14], Elovich Model [26], intraparticle diffusion model [27] and the power function technique [28].

\section{Results and Discussion}

The results of the experimentation and computation analysis of the kinetic modeling of the adsorption of naphthalene, benzene, toluene, ethylbenzene and xylene contaminated clay and sand are presented. The potential for the two sediments to adsorb and subsequently release the solutes for eventual mineralization by microbes have been exploited. The importance of this study was to explore the possible effects of sorption and bioavailability on biodegradation rates and the prediction of risk likely to occur from prolonged exposure of the soil to the contaminant solutes. The information on the mobility and hence availability of the chemicals is crucial in remediation studies as it determines the extent of partitioning and sequestration of the chemicals with sediments. A comparative analysis of the predictions from the kinetic modeling data obtained from experiments provided the basis for the choice of the applicable and suitable mechanisms for describing the adsorption and desorption processes.

\subsection{Equilibrium Time for Adsorption}

From Figure 1, the adsorption and desorption results showed that equilibrium was achieved at 28 and $20 \mathrm{hrs}$ for naphthalene in the clay and sand fractions respecttively. Similarly, for benzene, toluene, ethyl benzene and 


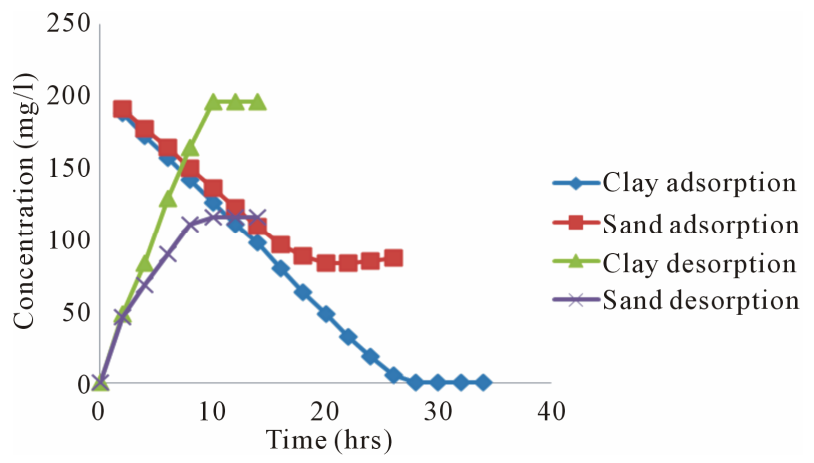

Figure 1. Variation of naphthalene concentration with time for adsorption and desorption.

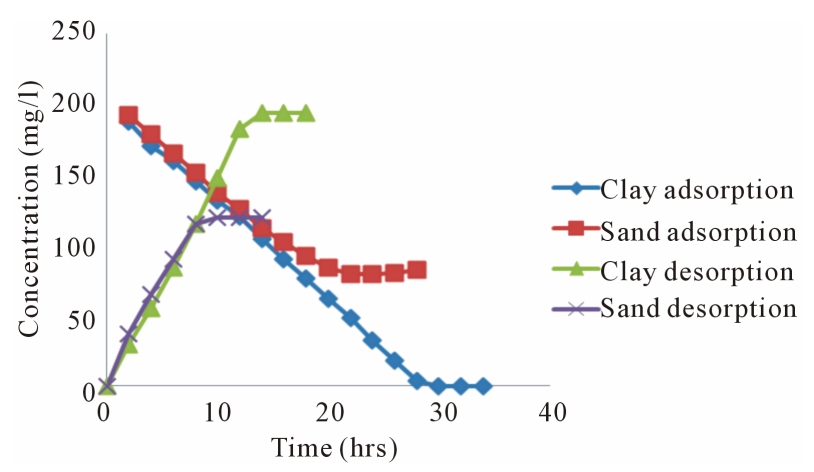

Figure 2. Variation of benzene concentration with time for adsorption and desorption.

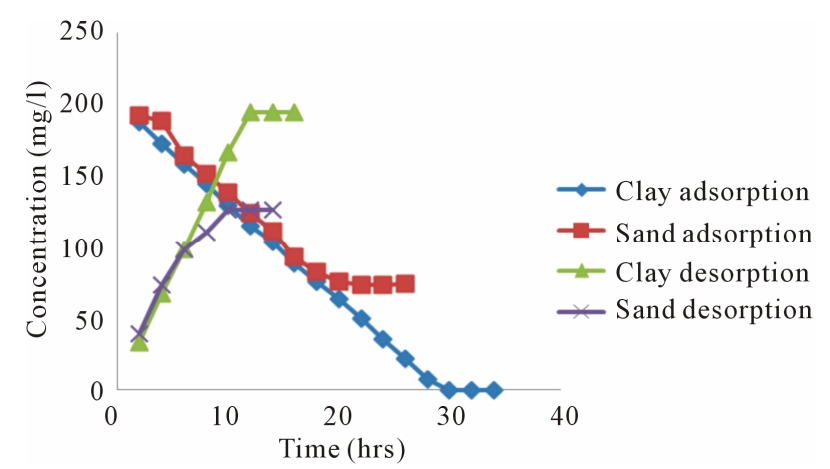

Figure 3. Variation of toluene concentration with time for adsorption and desorption.

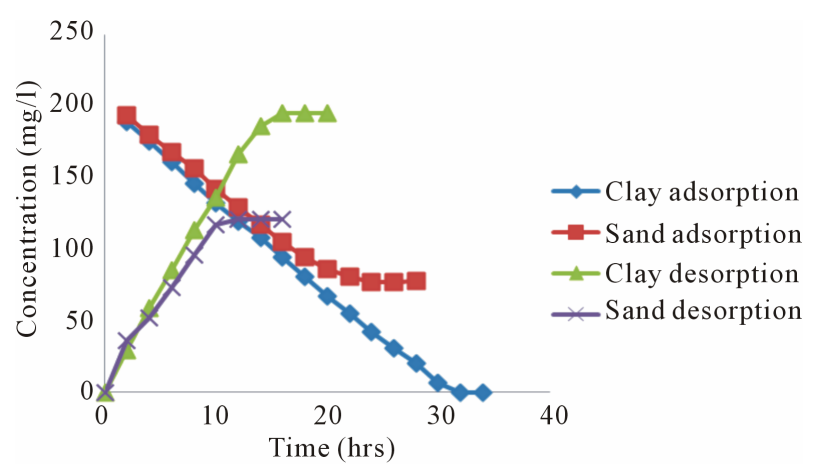

Figure 4. Variation of ethyl benzene concentration with time for adsorption and desorption.

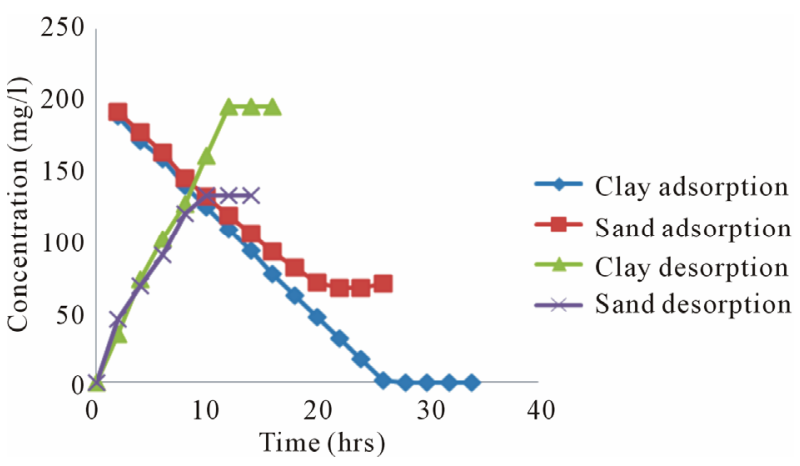

Figure 5. Variation of xylene concentration with time for adsorption and desorption.

xylene, equilibrium was attained at 30, 30, 32 and $28 \mathrm{hrs}$ and 22, 22, 24 and 22 hrs as shown in Figures 2-5 respectively. From the equilibrium time, sand was observed to reach equilibrium faster than clay for all of contaminant solutes used in this study. This can be attributed to its large pore spaces, intra-porous nature of sand (its pore spaces are connected to one another) and its higher permeability.

However, it is worthy to note that before equilibrium was attained for both clay and sand, the amount of naphthalene adsorbed in the clay sample was $102 \mathrm{mg}$ while in sand, the amount was $91 \mathrm{mg}$. Similarly, for benzene, toluene, ethyl benzene and xylene using clay, the amount adsorbed were 96, 97, 92 and $107 \mathrm{mg}$ while in sand, the amount adsorbed were 88, 89, 83 and $95 \mathrm{mg}$. Based on the amount adsorbed given equal time before equilibrium, clay would be described as a better adsorbing agent of naphthalene and BTEX than sand because it holds more of naphthalene, benzene, toluene, ethyl benzene and xylene. This property of clay over sand can be attributed to its larger surface area and higher porosity than sand [29, 30]. Sand has low porosity though not as many pore spaces because its grains are very large such that in a unit of sand, the fraction of soil volume that consists of holes is a lot less than for clay soil. Clay has many small pore spaces in which water containing the contaminant solutes remains clinging to the clay particle surfaces. Porosity is an important consideration when evaluating the potential volume of water or amount of hydrocarbons sediments may contain. Sediments with higher porosity typically have higher hydraulic conductivity, a property of sediments that describes the ease with which water can move through pore spaces.

\subsection{Equilibrium Time for Desorption}

Desorption equilibrium, for clay sediment, was achieved at $10 \mathrm{hrs}$ with $197 \mathrm{mg}$ of naphthalene desorbed, while using sand, equilibrium was achieved at 9 hrs with 116 $\mathrm{mg}$ of naphthalene desorbed. For benzene, toluene, ethyl benzene and xylene, in clay, equilibrium was achieved at 
$13 \mathrm{hrs}$ with $193 \mathrm{mg}$ of benzene desorbed, $12 \mathrm{hrs}$ with 194 $\mathrm{mg}$ of toluene desorbed, $15 \mathrm{hrs}$ with $195 \mathrm{mg}$ of ethyl benzene desorbed and $12 \mathrm{hrs}$ with $195 \mathrm{mg}$ of xylene desorbed respectively. While in sand, equilibrium was achieved at $9 \mathrm{hrs}$ with $119 \mathrm{mg}$ of benzene desorbed, $9 \mathrm{hrs}$ with $126 \mathrm{mg}$ of toluene desorbed $11 \mathrm{hrs}$ with $121 \mathrm{mg}$ of ethyl benzene desorbed and $10 \mathrm{hrs}$ with $132 \mathrm{mg}$ of xylene desorbed respectively.

Laboratory results obtained from this study affirmed that the desorption process was slow for both sediment types. The implication of this is that the organic chemicals are very slowly released for uptake or mineralization. The amount desorbed by the sediments may have been retarded as a result of their hydrophobicity. The solutes have a high affinity to sediments and great tendency to bind with organic carbon, mineral surfaces and interstitial voids within the micropores and submicropores of the sediment fraction [17,22,31], The observed slowly desorbing fraction can therefore be attributed to the effect of intraorganic matter and hindered pore diffusion mechanisms.

\subsection{Mechanism of Adsorption and Desorption Processes}

Tables 1-4 show the results of the kinetic modeling of the adsorption and desorption of naphthalene, benzene, toluene, ethyl benzene and xylene onto clay and sand used in this study. While the value of the reaction rate constant $\mathrm{k}$ predicted for the adsorption kinetics by the pseudo-first order and power function technique model equations closely approximated, there were however, wide deviations for the pseudo-second order, Elovich and intra-particle models. In contrast, for the desorption kinetics only the pseudo-first order and Elovich equations gave good fits as the intraparticle and power function equations were characterized by negative rate constants. The pseudo-second order rate constant was found to be ambiguous. However, estimations from the coefficient of regression indicate that the power function model best described the mechanism of adsorption of naphthalene, benzene, toluene, ethyl benzene and xylene while the intra-particle model gave the best description for desorption of naphthalene, benzene, toluene, ethyl benzene and xylene. They closely approximated to unity. Interestingly, the observed good approximations of the correlation coefficients obtained from the power function technique and intra-particle model for the contaminant solutes were consistent for both clay and sand sediments. This further affirms the suitability of the two models.

\section{Conclusion}

This study showed that adsorption and desorption of PAHs (naphthalene) and BTEX occurred in clay and sand with clay adsorbing more of the naphthalene, ben-

Table 1. Kinetic parameters and correlation coefficient $\left(R^{2}\right)$ values for the adsorption of naphthalene and BTEX using clay sediment.

\begin{tabular}{|c|c|c|c|c|c|c|}
\hline Kinetic Models & Parameters & Naphthalene & Benzene & Toluene & Ethyl benzene & Xylene \\
\hline & $k_{1}$ & 0.1210 & 0.116 & 0.136 & 0.095 & 0.150 \\
\hline \multirow[t]{3}{*}{ Pseudo-First Order } & $q_{e}$ & 3.7547 & 3.8729 & 7.0781 & 3.2904 & 4.8211 \\
\hline & $R^{2}$ & 0.8202 & 0.7510 & 0.8440 & 0.8550 & 0.6842 \\
\hline & $k_{2}$ & $4 \times 10^{-5}$ & $9 \times 10^{-5}$ & $1.3 \times 10^{-5}$ & $1.259 \times 10^{-5}$ & 0.00242 \\
\hline \multirow[t]{3}{*}{$\begin{array}{c}\text { Pseudo-Second } \\
\text { Order }\end{array}$} & $q_{e}$ & 43.1034 & 27.7778 & 23.6407 & -714.2857 & 30.8642 \\
\hline & $R^{2}$ & 0.0348 & 0.2087 & 0.3178 & 0.0002 & 0.056 \\
\hline & $\alpha$ & 1.2458 & 1.2933 & 1.3063 & 1.3317 & 1.2430 \\
\hline \multirow[t]{3}{*}{ Elovich } & $\beta$ & 0.2723 & 0.2572 & 0.2581 & 0.2454 & 0.2775 \\
\hline & $R^{2}$ & 0.9179 & 0.8974 & 0.9075 & 0.9051 & 0.9241 \\
\hline & $k_{p}$ & 0.496 & 0.483 & 0.477 & 0.469 & 0.496 \\
\hline \multirow[t]{3}{*}{ Intra-Particle } & $C$ & -0.737 & -0.746 & -0.723 & -0.739 & -0.718 \\
\hline & $R^{2}$ & 0.978 & 0.977 & 0.983 & 0.985 & 0.978 \\
\hline & $v$ & 1.013 & 0.981 & 0.981 & 1.022 & 1.009 \\
\hline \multirow[t]{2}{*}{ Power Function } & $k$ & 0.0684 & 0.0714 & 0.0684 & 0.0607 & 0.0702 \\
\hline & $R^{2}$ & 0.989 & 0.995 & 0.996 & 0.996 & 0.986 \\
\hline
\end{tabular}


Table 2. Kinetic parameters and correlation coefficient $\left(R^{2}\right)$ values for the adsorption of naphthalene and BTEX using sand sediment.

\begin{tabular}{|c|c|c|c|c|c|c|}
\hline Kinetic Models & Parameters & Naphthalene & Benzene & Toluene & Ethyl benzene & Xylene \\
\hline & $k_{1}$ & 0.1730 & 0.176 & 0.293 & 0.18 & 0.168 \\
\hline \multirow[t]{3}{*}{ Pseudo-First Order } & $q_{e}$ & 2.1706 & 2.6013 & 1.6023 & 3.0465 & 2.7020 \\
\hline & $R^{2}$ & 0.9240 & 0.914 & 0.934 & 0.917 & 0.909 \\
\hline & $k_{2}$ & 0.0016 & 0.0003 & 0.0033 & $4.996 \times 10^{-4}$ & $2 \times 10^{-5}$ \\
\hline \multirow[t]{3}{*}{$\begin{array}{l}\text { Pseudo-Second } \\
\text { Order }\end{array}$} & $q_{e}$ & 6.3776 & 13.3333 & -3.6657 & -9.9404 & -53.195 \\
\hline & $R^{2}$ & 0.1407 & 0.0436 & 0.1661 & 0.1045 & 0.0154 \\
\hline & $A$ & 2.419 & 1.9873 & 1.7778 & 1.9066 & 1.7794 \\
\hline \multirow[t]{3}{*}{ Elovich } & $B$ & 0.2054 & 0.2106 & 0.2120 & 0.2002 & 0.2325 \\
\hline & $R^{2}$ & 0.6067 & 0.9534 & 0.934 & 0.945 & 0.9472 \\
\hline & $k_{p}$ & 0.330 & 0.327 & 0.380 & 0.340 & 0.379 \\
\hline \multirow[t]{3}{*}{ Intra-Particle } & $C$ & -0.389 & -0.395 & -0.543 & -0.461 & -0.488 \\
\hline & $R^{2}$ & 0.958 & 0.964 & 0.920 & 0.974 & 0.974 \\
\hline & $V$ & 1.008 & 1.019 & 1.176 & 1.081 & 1.045 \\
\hline \multirow[t]{2}{*}{ Power Function } & $k$ & 0.056 & 0.0522 & 0.0374 & 0.0428 & 0.0555 \\
\hline & $R^{2}$ & 0.966 & 0.968 & 0.969 & 0.979 & 0.979 \\
\hline
\end{tabular}

Table 3. Kinetic parameters and correlation coefficient $\left(R^{2}\right)$ values for the desorption of naphthalene and BTEX using clay sediment.

\begin{tabular}{|c|c|c|c|c|c|c|}
\hline Kinetic Models & Parameters & Naphthalene & Benzene & Toluene & Ethyl benzene & Xylene \\
\hline & $k_{1}$ & 0.275 & 0.207 & 0.255 & 0.207 & 0.202 \\
\hline \multirow[t]{3}{*}{ Pseudo-First Order } & $q_{e}$ & -1.033 & -0.882 & -0.695 & -0.757 & 0.453 \\
\hline & $R^{2}$ & 0.922 & 0.852 & 0.796 & 0.877 & 0.893 \\
\hline & $k_{2}$ & 14.100 & 6.416 & 10.576 & 7.363 & 9.423 \\
\hline \multirow[t]{3}{*}{$\begin{array}{l}\text { Pseudo-Second } \\
\text { Order }\end{array}$} & $q_{e}$ & 0.018 & 0.035 & 0.029 & 0.027 & 0.025 \\
\hline & $R^{2}$ & 0.660 & 0.644 & 0.673 & 0.607 & 0.611 \\
\hline & $A$ & 2.558 & 2.646 & 2.604 & 2.688 & 2.688 \\
\hline \multirow[t]{3}{*}{ Elovich } & $B$ & 1.585 & 1.610 & 1.556 & 1.602 & 1.722 \\
\hline & $R^{2}$ & 0.937 & 0.883 & 0.904 & 0.912 & 0.913 \\
\hline & $k_{p}$ & -0.387 & -0.352 & -0.363 & -0.327 & -0.354 \\
\hline \multirow[t]{3}{*}{ Intra-Particle } & $C$ & 1.300 & 1.379 & 1.351 & 1.335 & 1.327 \\
\hline & $R^{2}$ & 0.983 & 0.969 & 0.975 & 0.983 & 0.982 \\
\hline & $V$ & -1.607 & -1.240 & -1.363 & -1.302 & -1.355 \\
\hline \multirow[t]{2}{*}{ Power Function } & $k$ & 0.979 & 0.977 & 0.993 & 1.112 & 0.989 \\
\hline & $R^{2}$ & 0.677 & 0.634 & 0.653 & 0.641 & 0.617 \\
\hline
\end{tabular}


Table 4. Kinetic parameters and correlation coefficient $\left(R^{2}\right)$ values for the desorption of naphthalene and BTEX using sand sediment.

\begin{tabular}{|c|c|c|c|c|c|c|}
\hline Kinetic Models & Parameters & Naphthalene & Benzene & Toluene & Ethyl benzene & Xylene \\
\hline & $k_{1}$ & 0.361 & 0.383 & 0.279 & 0.298 & 0.397 \\
\hline \multirow[t]{3}{*}{ Pseudo-First Order } & $q_{e}$ & 1.533 & -4.200 & 1.234 & 4.075 & -1.382 \\
\hline & $R^{2}$ & 0.885 & 0.826 & 0.992 & 0.825 & 0.763 \\
\hline & $k_{2}$ & 35.270 & 34.908 & 33.385 & 26.800 & 31.607 \\
\hline \multirow[t]{3}{*}{$\begin{array}{l}\text { Pseudo-Second } \\
\text { Order }\end{array}$} & $q_{e}$ & $8.67 \times 10^{-3}$ & $8.67 \times 10^{-3}$ & $8.91 \times 10^{-3}$ & $9.43 \times 10^{-3}$ & $8.82 \times 10^{-3}$ \\
\hline & $R^{2}$ & 0.729 & 0.719 & 0.669 & 0.660 & 0.719 \\
\hline & $\alpha$ & 5.076 & 4.329 & 4.237 & 4.484 & 4.065 \\
\hline \multirow[t]{3}{*}{ Elovich } & $\beta$ & 2.862 & 2.552 & 2.671 & 2.778 & 2.518 \\
\hline & $R^{2}$ & 0.948 & 0.958 & 0.974 & 0.921 & 0.948 \\
\hline & $k_{p}$ & -0.200 & -0.234 & -0.237 & -0.214 & -0.241 \\
\hline \multirow[t]{3}{*}{ Intra-Particle } & $C$ & 0.627 & 0.740 & 0.740 & 0.751 & 0.797 \\
\hline & $R^{2}$ & 0.980 & 0.981 & 0.984 & 0.978 & 0.978 \\
\hline & $V$ & -2.192 & -1.800 & -1.992 & -1.626 & -1.788 \\
\hline \multirow[t]{2}{*}{ Power Function } & $k$ & 0.600 & 0.429 & 0.624 & 0.549 & 0.610 \\
\hline & $R^{2}$ & 0.657 & 0.715 & 0.644 & 0.661 & 0.699 \\
\hline
\end{tabular}

zene, toluene, ethyl benzene and xylene than sand while sand desorbed more of the naphthalene, benzene, toluene, ethyl benzene and xylene than clay. The adsorptive property of clay over sand was attributed to its large surface area, higher porosity and high hydraulic conductivity of the adsorbates while the slow desorption can be attributed to its good binding sites (small pore sizes) that tend to hold the adsorbates to its particles. For both adsorption and desorption, equilibrium was attained faster for sand than for clay as a result of the higher permeability of sand sediment. The power function model gave the best description for the adsorption mechanism of naphthalene, benzene, toluene, ethyl benzene and xylene, while the intraparticle model was most suitable for describing the mechanism of desorption of the contaminant solutes.

\section{REFERENCES}

[1] D. T. Sponza and R. Oztekin, "Destruction of Some More and Less Hydrophobic PAHs and Their Toxicities in a Petrochemical Industry Wastewater with Sonication in Turkey," Bioresource Technology, Vol. 101, No. 22, 2010, pp. 8639-8648. doi:10.1016/j.biortech.2010.06.124

[2] J. D. Stokes, G. I. Paton and K. T. Semple, "Behavior and Assessment of Bioavailability of Organic Contaminants in Soil: Relevance for Risk Assessment and Remediation," Soil Use and Management, Vol. 21, No. S2, 2006, pp. 475-486. doi:10.1079/SUM2005347

[3] W. Chen, L. Cong, H. Hu, P. Zhang, J. Li, Z. Feng, A. T. Kan and M. B. Tomson, "Release of Adsorbed Polycyclic Aromatic Hydrocarbons under Cosolvent Treatment: Implications for Availability and Fate," Environmental Toxicology and Chemistry, Vol. 27, No. 1, 2008, pp. 112-118. doi:10.1897/07-170.1

[4] J. Yan, L. Wang, P. P. Fu and H. Yu, "Photomutagenicity of 16 Polycyclic Aromatic Hydrocarbons from the US EPA Priority Pollutant List," Mutation Research/Genetic Toxicology and Environmental Mutagenesis, Vol. 557, No. 1, 2004, pp. 99-108. doi:10.1016/j.mrgentox.2003.10.004

[5] H. K. Bojes and P. G. Pope, "Characterization of EPA's 16 Priority Pollutant Polycyclic Aromatic Hydrocarbons (PAHs) in Tank Bottom Solids and Associated Contaminated Soils at Oil Exploration and Production Sites in Texas," Regulatory Toxicities and Pharmacology, Vol. 47, No. 3, 2007, pp. 288-295. doi:10.1016/j.yrtph.2006.11.007

[6] M. C. Bruzzoniti, M. Fungi and C. Sarzanini, "Determination of EPA's Priority Pollutant Polycyclic Aromatic Hydrocarbons in Drinking Waters by Solid Phase Extraction-HPLC," Analytical Methods, Vol. 21, No. 6, 2010, pp. 739-743. doi:10.1039/b9ay00203k

[7] S. Mitra and R. Pranab, "BTEX: A Serious Ground Water Contaminant," Research Journal of Environmental Sciences, Vol. 5, 2011, pp. 394-398. doi:10.3923/rjes.2011.394.398

[8] E. F. Neuhauser, J. P. Kreitinger, D. V. Nakles, S. B. 
Hawthorne, F. G. Doherty, U. Ghosh, M. F. Khalil, R. S. Ghosh, M. T. O. Jonker and S. A. Van der Heijden, "Bioavailability and Toxicity of PAHs at MGP Sites," Land Contamination and Reclamation, Vol. 14, No. 2, pp. 261266. doi:10.2462/09670513.713

[9] C. N. Owabor, S. E. Agarry and T. O. Azeez, "Development of a Transport Model for the Microbial Degradation of Polycyclic Aromatic Hydrocarbons in a Saturated Porous Medium," Journal of the Nigerian Association of Mathematical Physics, Vol. 16, No. 2, 2010, pp. 317-324.

[10] W. Zhang, E. J. Bouwer and W. P. Ball, "Bioavailability of Hydrophobic Organic Contaminants: Effects and Implications of Sorption-Related Mass Transfer on Bioremediation," Ground Water Monitoring \& Remediation, Vol. 18, No. 1, 1998, pp. 126-138.

[11] C. N. Owabor, S. E. Ogbeide and A. A. Susu, "Adsorption and Desorption Kinetics of Naphthalene, Anthracene and Pyrene in Soil Matrix," Petroleum Science and Technology, Vol. 28, No. 5, 2010, pp. 504-514. doi:10.1080/10916460802108546

[12] C. N. Owabor, S. E. Ogbeide and A. A. Susu, "Estimation of Transport and Degradation Parameters for Naphthalene and Anthracene: Influence of Mass Transfer on Kinetics," Environmental Monitoring and Assessment, Vol. 169, No. 1-4, 2010, pp. 607-617. doi:10.1007/s10661-009-1200-6

[13] S. Y. Gebremariam, "Mineralization, Sorption and Desorption of Chlorpyrifos in Aquatic Sediments and Soils," Ph.D. Thesis, Washington State University, Pullman, 2011.

[14] C. F. Chang, C. Y. Chang, K. H. Chen, W. T. Tsai, J. L. Shie and Y. H. Chen, "Adsorption of Naphthalene on Zeolite from Aqueous Solution," Journal of Colloid and Interface Science, Vol. 277, No. 1, 2004, pp. 29-34. doi:10.1016/j.jcis.2004.04.022

[15] Z. Yu, W. Huang, J. Song, Y. Qian and P. Peng, "Sorption of Organic Pollutants by Marine Sediments: Implication for the Role of Particulate Organic Matter," Chemosphere, Vol. 65, No. 11, 2006, pp. 2493-2501. doi:10.1016/i.chemosphere.2006.04.036

[16] R. S. Kookana, "The Role of Biochar in Modifying the Environmental Fate, Bioavailability and Efficacy of Pesticides in Soils: A Review," Soil Research, Vol. 48, No. 7, 2010, pp. 627-637. doi:10.1071/SR10007

[17] C. N. Owabor and J. O. Osarumwense, "Pyrene Mineralization in Clay Soil with and without Organic Carbon: The Role of Adsorption and Desorption Kinetics Equilibria," Global Journal of Pure and Applied Sciences, Vol. 14, No. 1, 2008, pp. 109-113. doi:10.4314/gjpas.v14i1.16782

[18] H. M. Lesan and A. Bhandari, "Atrazine Sorption on Surface Soils: Time-Dependent Phase Distribution and Apparent Desorption Hysteresis," Water Research, Vol. 37, No. 7, 2003, pp. 1644-1654. doi:10.1016/S0043-1354(02)00497-9

[19] P. Wang and A. A. Keller, "Sorption and Desorption of Atrazine and Diuron onto Water Dispersible Soil Primary
Size Fractions," Water Research, Vol. 43, No. 5, 2009, pp. 1448-1456. doi:10.1016/j.watres.2008.12.031

[20] W. J. Weber Jr. and J. C. Morris, "Kinetics of Adsorption on Carbon from Solution," Journal of the Sanitary Engineering Division, Vol. 89, No. 2, 1963, pp. 31-59.

[21] J. J. Pignatello and B. Xing, "Mechanisms of Slow Sorption of Organic Chemicals to Natural Particles," Environmental Science \& Technology, Vol. 30, No. 1, 1996, pp. 1-11. doi:10.1021/es940683g

[22] W. Huang, "Effects of Organic Matter Heterogeneity on Sorption and Desorption of Organic Contaminants by Soils and Sediments," Applied Geochemistry, Vol. 18, No. 7, 2003, pp. 955-972.

[23] W. L. McCabe, J. C. Smith and P. Harriot, "Unit Operations of Chemical Engineering," 7th Edition, McGrawHill, New York, 2005, pp. 836-888.

[24] C. N. Owabor and S. E. Agarry, "Sorption Behaviour of Naphthalene in Clay and Coarse Sediments Kinetic and Equilibrium Studies," Nigerian Journal of Applied Science, Vol. 27, 2009, pp. 15-23.

[25] R. Sivaraj, C. Namasivayan and K. Kadirvelu, "Orange Peel as an Adsorbent in the Removal of Acid Violet 17 (Acid Dye) from Aqueous Solution," Water Management, Vol. 21, No. 1, 2001, pp. 105-110.

[26] M. N. Sahmoune, K. Louhab and A. Boukhiar, "Kinetic and Equilibrium Models for the Biosorption of $\mathrm{Cr}$ (III) on Streptomyces rimosus," Journal of Applied Sciences Research, Vol. 3, No. 4, 2008, pp. 294-301.

[27] W. J. Weber and T. M. Young, "A Distribute Reactivity Model for Sorption by Soils and Sediments. 6. Mechanistic Implications of Desorption under Supercritical Fluid Conditions," Environmental Science and Technology, Vol. 31, No. 6, 1997, pp. 1686-1691. doi:10.1021/es9605681

[28] S. Singh, L. K. Verma, S. S. Sambi and S. K. Sharma, "Adsorption Behavior of Ni(II) from Water onto Zeolite $\mathrm{X}$ : Kinetics and Equilibrium Studies," Proceedings of the World Congress on Engineering and Computer Science, 22-24 Octber 2008, San Francisco, pp. 112-117.

[29] C. W. Curry, R. H. Bennett, M. H. Hulbert, K. J. Curry and R. W. Faas, "Comparative Study of Sand Porosity and a Technique for Determining Porosity of Undisturbed Marine Sediment," Marine Georesource and Geotechnology, Vol. 22, No. 4, 2004, pp. 231-252. doi: $10.1080 / 10641190490900844$

[30] C. N. Owabor, I. O. Oboh and F. A. Omiojieahior, "Adsorption Isotherms for Naphthalene on Clay and Silt Soil Fractions: A Comparison of Linear and Nonlinear Methods," Advanced Materials Research, Vol. 367, 2012, pp. 359-364. doi:10.4028/www.scientific.net/AMR.367.359

[31] U. V. Okere and K. T. Semple, "Biodegradation of PAHs in 'Pristine' Soils from Different Climate Region," Journal of Bioremediation \& Biodegradation, Vol. 3, 2012, p. 145. 